\title{
Supernumerary Teeth in all 4 Quadrants of a Non- Syndromic Patient with a Positive Family History: A Case Report
}

\author{
Ezinne Ogbureke*, Stephen Laman, Shawn Adibi and Cleverick D Johnson \\ Department of General Practice and Dental Public Health, The University of Texas School of Dentistry, Houston, Texas, USA
}

Received: July 03, 2014; Accepted: July 31, 2014; Published: August 30, 2014

*Corresponding author: Dr. Ezinne Ogbureke, Department of General Practice and Dental Public Health, The University of Texas School of Dentistry, Houston, Texas, USA, Tel: 7134864261; Email: ezinne.i.ogbureke@uth.tmc.edu

\begin{abstract}
Human growth and development of dentition generally follows an orderly pattern of an eruption sequence of primary dentition of 20 teeth, followed by an interim time of mixed dentition and concluding with 32 permanent teeth. The literature is rich with descriptions of variation of this pattern largely based on addition or deletion of the genetic code which may include geographic isolation and or unexplained point mutations. Generally tooth eruption follows, concluding with the 3rd molar Layman's terminology "wisdom tooth" by age 25 . The literature describes patients with extra teeth referred to as supernumerary teeth. Common patient's diagnosis for additional teeth includes syndromes such as Cleidocranial dysplasia or Gardner's Syndrome. In some patients as with this case report, the finding doesn't seem to point out the existence of a syndrome.

This paper highlights a case of 6 supernumerary teeth located in all 4 quadrants of a patient with a positive family history of supernumerary teeth, who came in for a routine new patient screening at The New Patient Diagnostic Clinic" of theUniversity of Texas School of Dentistry at Houston. His subsequent treatment plan is discussed as well as a brief review of literature for supernumerary teeth.
\end{abstract}

Keywords: Multiple supernumerary teeth; Extra teeth; Hyperdontia; Mesiodens ; Non syndromic

\section{Introduction}

Hyperdontia is defined as the possession of more teeth beyond the normal complement of dentition and these extra teeth are referred to as supernumerary teeth [1]. Studies have shown a higher rate of occurrence in males than females [1-4] without any conclusive explanation to the reason in this gender preference. The incidence in primary dentition is less than in the permanent dentition and ranges between $0.3 \%$ and $0.8 \%$, and in permanent dentition, between $0.1 \%$ and $3.8 \%$ according to the population studied $[2,4]$. Supernumerary conditions can occur in any location, but they have a predilection for the maxilla [1-4] and approximately $76-86 \%$ of cases occur as single tooth supernumerary [5]. In a study of 152 child cases in a Jordanian population, $90 \%$ of the supernumerary teeth where found in the premaxilla area and while $77 \%$ of the subjects had just one supernumerary, $18.4 \%$ had two and $4.6 \%$ had three or more [2]. Mesiodens, defined as a supernumerary tooth located predominately in the premaxilla area between the two upper centrals are the most commonly encountered supernumerary tooth in children occurring in $0.15 \%$ to $1.9 \%$ of population $[1,4,6]$. These extra teeth could be fully formed and resembling the tooth adjacent to its location or rudimentary, the commonest shape being conical. They could be erupted, partially erupted or impacted. The commonest location of these teeth is the upper anterior central area followed by the upper premolar area in studies. While these teeth commonly are located in the tooth bearing area when they occur, there are documentations of ectopic locations such as the paranasal sinuses or the nasal cavity. Multiple supernumerary teeth on a non syndromic patient is a rare phenomenon, a search on an online repository produced only 18 results and of the 18 cases only 3 by Batra et al. [7], Babu et al. [8] and Desai and Shah [9] had associated family history of similar occurrence thereby making this an interesting topic for further genetic analysis. Supernumeraries can be classified by their position as mesiodens, paramolars, distomolars or parapremolars [10]. They maybe single, multiple, unilateral, bilateral, erupted or unerupted and can affect upper or lower jaws [11]. They can also be described based on their form [3] as

Conical - The commonest presentation, seen in $69.6 \%$ of cases and as the name implies, shaped like a cone with fully formed roots [3].

Tuberculate - These are barrel shaped, with incomplete roots and usually impacted while preventing eruption of other teeth. Found in $17.7 \%$ of cases [12].

Supplemental - These resemble adjacent teeth and occurs in about $11.3 \%$ of cases [12].

Compound and Complex Odontomas - Multiple supernumerary teeth are uncommon without associated syndromes and the commonest syndromes associated with supernumerary teeth are Gardner's syndrome (up to $20 \%$ may express clinical signs such as supernumerary teeth), 
Cleidocranial dysplasia as well as cleft lip palate [1,2,5,11]. Other rarer syndromes with associated hyperdontia include Ehler Danlos, Fabry-Anderson and Crouzon's syndrome.

It is important to rule out associated syndromes for many supernumerary conditions because the morbidity and sometimes fatal implications may warrant medical care, genetic counseling for the patients and their families.

\section{Case Report}

A 35 year old male presented to the Diagnostic clinic at University of Texas School of Dentistry (UTSD) wanting to be a patient of the school. Using the American Society of Anesthesiologists classification, patient was determined to be ASA 1 (Healthy patient with no systemic diseases). Extra oral and head and neck examinations revealed no abnormalities. Intraorally, the patient had no obvious soft tissue pathology and dental hard tissue examination revealed the presence of several supernumerary teeth amongst other findings. On the upper right quadrant, there is a fully erupted supernumerary buccal of \#2 and another palatal of \#5. On the upper left quadrant there is an impacted microdont between \#12 and 13 while on the lower left quadrant features a lingually placed supplemental premolar between \#20 and 21 and the lower right had two extra premolars Figures: 1,2,3,4. A total of 6 supernumeraries with 5 erupted and 1 impacted. Patient's family history from questioning was

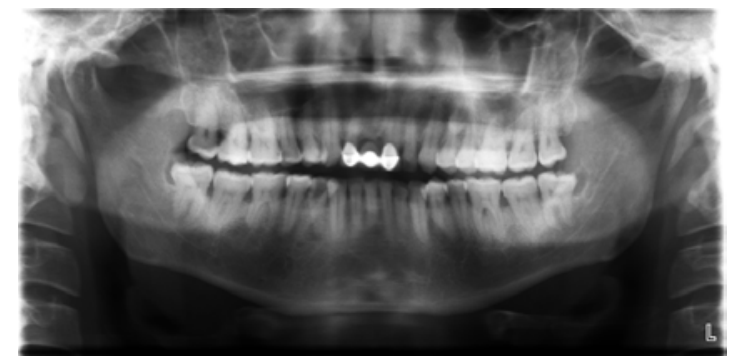

Figure 1: Panoramic radiograph showing supernumerary teeth in premolar areas of lower left and right quadrants.
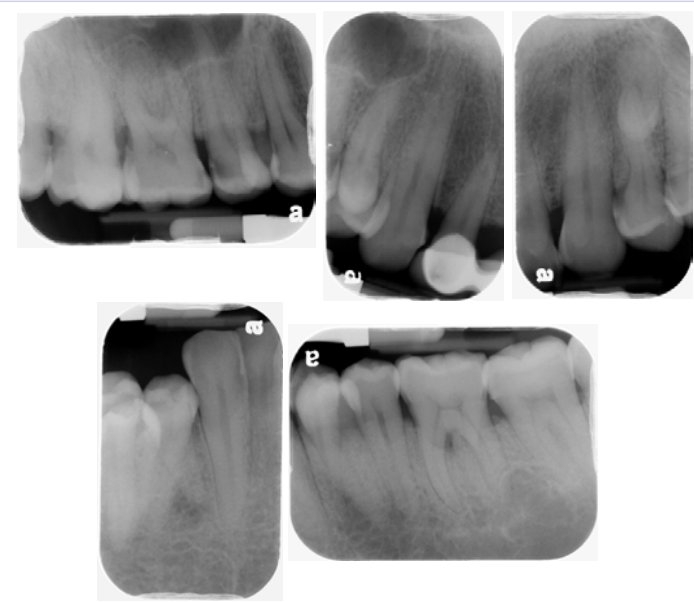

Figure 2: Periapical radiographs showing supernumerary teeth adjacent to \#5 on the upper right, an impacted tooth adjacent to \#12 on the upper left and in the lower premolar areas.

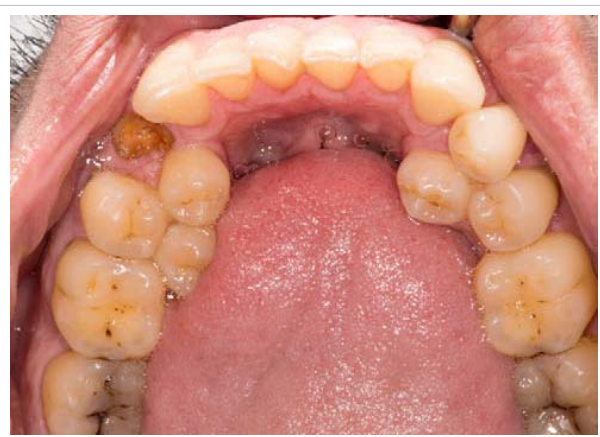

Figure 3: Showing two extra premolars lingual of the lower right premolar area and one in the same location on the lower left quadrant.

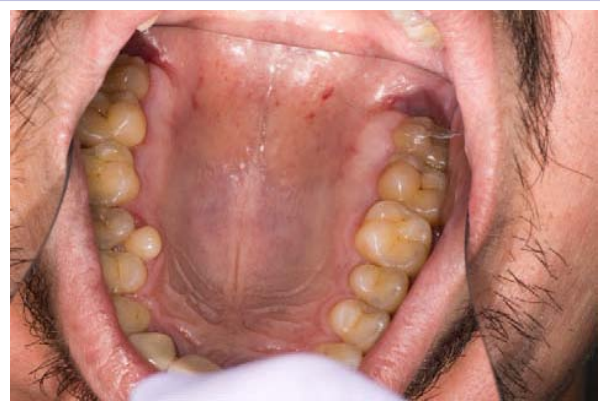

Figure 4: Showing rudimentary supernumerary palatal of the upper right premolars .

positive for supernumerary teeth. He reported that his mother and two sisters had at least three extra teeth each. The patient has a 3 unit bridge replacing \#8 (upper right central incisor) and a dental history reveals he had a tooth extracted in the area. It is important to highlight that patient was of normal stature with no facial or clavicular features of cleidocranial dysplasias like frontal and parietal bossing, hypertelorism, hypoplastic clavicles. His panoramic radiographs had no multiple impactions of cleidocranial dysplasias and Gardner's neither were there any jaw radiopacities indicative of presence of jaw osteomas, a diagnostic feature of Gardner's syndrome [13].

\section{Discussion}

The precise etiology of supernumeraries is not known and different theories abound as to their possible origin [12]. The theory of atavism which postulates that supernumeraries represent a relic of extinct ancestors with more compliment of teeth than exists today is no longer popular and a second theory of dichotomy says that a tooth bud divides to form a supernumerary $[2,12]$. Heredity is also thought to play a role in development of supernumeraries [2]. However, the most widely supported view is that they arise from proliferation of the dental lamina $[12,14]$. Studies show a higher male to female ratio [1-4] and our patient is a male. Most supernumerary teeth, as much as $75-95 \%$ are impacted $[1,2,14]$ but in this patient, out of the 6 supernumerary teeth present, five are erupted with one impacted. While the premaxila area is the commonest location for supernumeraries, the premolar is considered to be the second commonest [3]. Yusof [15] in a systemic literature review also identified the premolar 
region as the commonest region for multiple supernumerary teeth in non-syndromic patients coinciding with our findings in this patient where 5 of the 6 supernumerary teeth were located in the premolar region of all four quadrants. Patient had a history of a 'small tooth' being extracted in his upper anterior area and the authors suspect it could have been a mesiodens. It was not clearly stated how and if \#8 (upper right central incisor) was lost. Based on description, the three supernumeraries on the lower right and left quadrants as well the one buccal of \#2 (not clearly pictured) could be described as supplemental para premolars and paramolar while that situated palatally on the upper right quadrant could be described as conical in Figures: 3 and 4 .

\section{Treatment Strategies}

Treatment planning for a patient with multiple supernumerary teeth can be challenging due to the extent and possible severity of inherent malocclusion requiring a multidisciplinary approach for treatment. In this case caries risk, partial impactions of mandibular third molars and irregularly conical shaped form of clinical crowns have added another wrinkle to the planning of the treatment. In some cases, if patient desires, orthodontic considerations may be needed to correct occlusion and achieve a more functional and esthetic outcome where possible. The treatment plan for this patient is a multi-disciplinary approach and includes operative procedures for caries, extraction of all four 3rd molars and the grossly carious \#28, an orthodontic consult for possible movement of one of the supplementals into the space for \#28 and extraction of the remaining supernumerary except the impacted microdont on the upper left side which is asymptomatic at this time but should it become symptomatic subsequently, it would have to be surgically removed.

Consequences of supernumerary teeth include malocclusion, impactions, retained primary dentition and cyst formation [12] There have also been documented cases of ectopic supernumerary teeth in the maxillary sinus and nasal cavity with associated symptoms of nasal discharge, epistaxis, headaches, facial pain, numbness and hemoptysis [7,16-18]. It is not uncommon for the patients to have a high caries rate due to the crowding and subsequent difficulty in maintaining good hygiene. Impacted supernumeraries could also cause root resorption on adjacent tooth while some may delay or prevent eruptions of permanent teeth $[7,19]$ prompting their surgical removal.

In this patient, the presence of supernumerary teeth on the lower right quadrant seemed somewhat a blessing as the extra tooth could be orthodontically moved into the space to replace \#28 after its extraction.

The absence of sebaceous cysts, multiple jaw osteomas, odontomas and multiple impactions on the panoramic radiograph eliminates the possibility of Gardner's syndrome. Patient was of normal height, showed no clavicular hypoplasia, frontal and parietal bossing, hypertelorism or depressed nasal bridge, hypodontia, multiple impactions and other features characteristic of Cleidocranial dysplasia. The presence of a positive family history of supernumeraries in this case patient however, opens up an avenue for a possible further investigation.
Multiple supernumeraries in a non syndromic patient is rare. A search of International literature on an online repository for "multiple supernumerary teeth on a non syndromic patient" yielded 18 results out of which only 3 of the reported cases had a positive family history. In one of these three cases as documented by Batra et al. [7], family history of multiple supernumeraries has been reported as inheritable in an autosomal dominant fashion.

\section{Conclusion}

Clinical cases of patients with supernumerary teeth should prompt inquiry into the possibility of correlated genetic syndrome. Furthermore, this should trigger other workup procedures such as additional imaging/X-ray investigations into the possibility of other related extra bony conditions. Where genetic correlate is identified, there may be the necessity to involve genetic counselors in the management of these patients.

\section{Acknowledgement}

We would like to thank Ms Kalyopy Emmanouil for her assistance in providing the patient for the case report.

\section{References}

1. Yagüe-García J, Berini-Aytés L, Gay-Escoda C. Multiple supernumerary teeth not associated with complex syndromes: a retrospective study. Med Oral Patol Oral Cir Bucal. 2009; 14(7):E331-6.

2. Rajab LD, Hamdan MA. Supernumerary teeth: review of the literature and a survey of 152 cases. Int J Paediatr Dent. 2002; 12(4):244-54.

3. Ferrés-Padró E, Prats-Armengol J, Ferrés-Amat EA. Descriptive study of 113 unerupted supernumerary teeth in 79 pediatric patients in Barcelona. Med Oral Patol Oral Cir Bucal. 2009; 14(3):E146-52.

4. Leco Berrocal MI, Martín Morales JF, Martínez González JM. An observational study of the frequency of supernumerary teeth in a population of 2000 patients. Med Oral Patol Oral Cir Bucal. 2007; 12:E134-8.

5. Neville B, Damm D, Allen C, Bouquot. J. Oral and maxillofacial pathology. 3rd ed. Philadelphia: WB Saunders; 2008.

6. Sapp JP, Eversole LR, Wysocki GP. Contemporary Oral and Maxillofacial Pathology. 2nd ed. St. Luis: Mosby; 2004.

7. Batra P, Duggal R, Parkash H. Non-syndromic multiple supernumerary teeth transmitted as an autosomal dominant trait. J Oral Pathol Med. 2005; 34(10):621-5.

8. Babu V, Nagesh KS, Diwakar NR. A rare case of hereditary multiple impacted normal and supernumerary teeth. J Clin Pediatr Dent. 1998; 23(1):59-61.

9. Desai RS, Shah NP. Multiple supernumerary teeth in two brothers: a case report. J Oral Pathol Med. 1998; 27(8):411-3.

10. Arathi R, Ashwini R. Supernumerary teeth: a case report. J Indian Soc Pedod Prev Dent. 2005; 23(2):103-5.

11. Srivatsan P, Aravindha BN. Mesiodens with an unusual morphology and multiple impacted supernumerary teeth in a non - syndromic patient. Indian J Dent Res. 2007; 18(3):138-40.

12. Russell KA, Folwarczna MA. Mesiodens-diagnosis and management of a common supernumerary tooth. J Can Dent Assoc. 2003; 69(6):362-6.

13. Maxx RE, Stern D. Oral and Maxillofacial Pathology: A rational for 
diagnosis and treatment. Quintessence: Chicago; 2003.

14. Refoua Y, Arshad M. An unusual case of bilateral maxillary and mandibular supernumerary teeth. J Dent Tehran U Med Sci. 2006; 3:140-2.

15. Yusof WZ. Non-syndrome multiple supernumerary teeth: literature review. J Can Dent Assoc. 1990; 56(2):147-9.

16. Chamyal PC. Intranasal supernumerary tooth. Indian J Otolaryngol Head Neck Surg. 1997; 49(1):54-6. doi: 10.1007/BF02991715.
17. Erkmen N, OlmezS , Onerci M. Supernumerary tooth in the maxillary sinus: case report. Aust Dent J. 1998; 43:385-386.

18. Saleem T, Khalid U, Hameed A, Ghaffar S.Supernumerary. Ectopic tooth in the maxillary antrum presenting with recurrent haemoptysis. Head Face Med. 2010; 6:26. doi: 10.1186/1746-160X-6-26.

19. Cogulu D, Yetkiner E, Akay C, Seckin O, Alpoz R. Multidisciplinary management and long-term follow-up of mesiodens: a case report. J Clin Pediatr Dent. 2008; 33(1):63-6. 